\title{
On Methods to Motivate College Students in Elementary Class under Level
}

\author{
Based on College English Teaching
}

\author{
Jiaoyan Yang \\ Chengdu Campus of Sichuan Agricultural University \\ Chengdu, China 610000
}

\begin{abstract}
In view of level-based English teaching in other Universities, Sichuan Agricultural University has conducted its own unique level-based English teaching based on its own situations. In order to solve the problems arising after the implementation of level-based English teaching, Dornyei's Motive Theory has been applied to research how to motivate students in elementary class to study English hard.
\end{abstract}

Keywords-level-based English teaching; Sichuan Agricultural University; motive; Dornyei 's Motive Theory

\section{INTRODUCTION}

The expansion of college enrollment dramatically increases the number of college students, which leads to the great differences in students' English level. Given the situations, College English Course Requirements issued by National Education Department in 2007 clearly demonstrates that level-based English teaching should be applied in college English teaching in order to adapt to individualized education and meet the practical needs to improve students' comprehensive English application. As far as the teaching requirements are concerned, three levels and three kinds of requirements have been put forward, namely, general requirements, higher and the highest ones. Confronted with students with various English levels, all universities carry out their own styles of level-based English teaching according to the newly-issued requirements. Level-based college English teaching has increasingly demonstrated its advantages compared to the past traditional non-discriminative teaching mode, but it has exposed some common problems:

1) Freshmen are divided according to their English scores in the College Entrance Exams, which deprives them of the chances to utilize the new college conditions to improve their English, so they feel frustrated when they just start their college life.

2) It is hard for monitors to lead and supervise their classmates for their classmates are divided into different English classes based on their English levels.

3) It is unfair to assess students' grades since they attend different English classes and exams.

4) Students in the elementary English class lack selfdisciplines, motives and competition so that they fail to interact with teachers in class and converse with teachers after class.

In order to avoid these problems, Sichuan Agricultural University has implemented its own special level-based English teaching model. Students have English classes together at the first term, then are divided based on their scores in CET4 at the second term. If students pass CET4,then they are encouraged to choose other intermediate or advanced English courses without taking the college English course; if not, they will stay in the original class and continue to do the course. At the first term of the second year, the same kind of student division will occur again. All students will have the same test from the database but their regular performance occupies different proportion according to their English level. All these measures can effectively avoid the former-mentioned first three problems to a certain degree, yet the forth problem is still not solved. As a result, the article focuses on how to motivate students in the elementary English class to study hard.

\section{LEARNING MOTIVE THEORY}

China's English learning belongs to foreign language learning, which is not a second language acquisition; therefore Chinese students are learning English under the insufficient foreign language input. Consequently, the article applies Dornyei 's Motive Theory to research the level-based English teaching in Sichuan Agricultural University for his theory is the only motive theory directly connected with foreign language teaching. Dornyei (2001) thinks that motive is the key factor which affects the learning effectiveness of foreign language learners. In addition, as early as 1994,he put forward the three fundamental elements in the process of the foreign language learning (foreign language, language learners and language learning environment) and three-level foreign-language-learning motive mode which demonstrates the three factors of language(social, individual and educational factors).

Dornyei (1994) points out that the foreign-languagelearning motive mode embodies three factors: language, language learners and language learning environment. The motive concerning the foreign language includes every elements related to the language, such as the value and vigor of the foreign language. Dornyei (1994) think the motive 
concerning the language involves two systems: integrative motive and instrumental motive. The former concerns the language learners' emotions towards the language, which demonstrates "a kind of sincere individual interests in the culture and people of the foreign language" (Lambert,1974,p.98); the latter involves the goals achieved by learning the foreign language, which is related to the individual future development. The evaluation of the foreign language values from the perspective of motive concerning the language illustrates the social and practical features of the language, which provides the answer to why people want to learn the foreign language. The motive about the language learners include various factors related to the language learners, such as self -efficacy, self-confidence, attitudes toward study and achievement attribution. The research on the kind of motive shows the motive is closely related to the learners' understanding of themselves, which shows whether the language learners can finish the learning. The motive concerning the language learning environment is shown as learners' attitudes towards the language course, language instructors and learning groups, which involves the three special motive factors: the course, the instructor and the learning group. The course motive includes a series of factors such as the choice of course books, arrangements of the course and the organization of the teaching, which shows the relevance between the learner's individual expectation and the language course and directly affects the learners' interests in the course. The instructor motive is shown as the instructor's teaching methods and styles, personalities and attention to the learners. Learning group motive reflects the influence of the learning group on the learners. Learning environment motive reveals the language-teaching environment under which the language learner can acquire the language.

In addition, Dornyei introduces a new issue in the research on foreign language learning motive based on motive deficiency research prospering in 1990s (Dornyei, 2011, p.139-149). He thinks that motive deficiency research "focuses more on a series of external factors, which weak the behavioral intention or the motive base of a certain occurring behavior" (Dornyei,2001,p.143).And he first definitely defined motive deficiency as a specific external factor which makes people reduce or lose motive. Based on his research of interview type on fifty students who are labeled by their classmates and teachers as those who lack learning motives, he summarizes nine main reasons leading to motive deficiency:

- The instructor factors, which include the defects of the instructors' personality, work attitude, personal ability and teaching methods;

- School teaching administration, which includes large classes, unreasonable level-based teaching, deficiency of teachers and improper course arrangements.

- Deterioration of self-confidence caused by past failures or lack of success;

- Learners' negative attitudes towards language learning;
- Learners' dissatisfaction about the compulsory foreign language learning;

- Effects of other language that the learners are studying;

- Learners' negative attitudes toward the learning group which they are in;

- Learners' negative attitudes toward other learners;

- Course books chosen. Within the nine factors, the instructor factors have the greatest effect on learners' motive deficiency.

\section{LEARNING MOTIVE ANALYSIS OF STUDENTS IN ELEMENTARY CLASS}

Students in elementary class here refer to sophomores in Sichuan Agricultural University who continue to do the college English course in the first term after the level-based English teaching is implemented. Based on Dornyei's motive theory, the author has conversed with twenty students who have been labeled as those lacking learning motives and analyzed their foreign language learning motives.

\section{A. Language Motives}

The instrumental motives of these students are comparatively strong, which is proved by the fact that they all want to pass CET 4 and meet the requirement of the university to obtain their Bachelor's degrees but on the other hand they are dissatisfied that English is a required foundation course and is regarded as a criterion to judge whether they can obtain their degrees. In their view, they study English just to pass the exam. Except that, English is of no use to their future work and life, which is proved by their own words - “I don't plan to study abroad, pursue postgraduate education or work in the multinational corporation, so it is a waste of my youth to study English". Compared to their instrumental motives, their integrative motives are obviously weaker. They are not interested in the English language itself or the culture of English-speaking countries, therefore they often say, "We, as Chinese, haven't had such a good command of our own complex language and magnificent culture that I don't care about other useless foreign language and culture."

\section{B. Learner' Motive}

Some students have lacked confidence in their English learning, even felt inferior to others. For one thing, they have never got satisfactory English grades-"as far as I can remember, it is rare for me to pass the exam", for another, they attribute their failure in English learning to their lack of talents. They think they have spared no energy to study English since they entered the college-ci get up early to study English, recite words, practice listening and do the CET 4 simulated tests every day, but have failed to pass the exam twice". As a result, the majority of students conclude that they are not such a material to study English that they can't learn English well. As time goes by, they increasingly dislike the learning of English, even want to skip classes- 
"If the teacher doesn't cut my scores, I don't want to have the class."

\section{Learning Environment Motive}

Some students think the course book chosen is too hard to study. They think there are so many unknown words in the texts - "finding there are several pages of words after the texts, I lose the gut to read the text." Besides, the exercises after the texts are so difficult that they cannot finish them on their own- "I don't know many words in the exercises and the choices so that I cannot do many of them."Because they think the contents of the course book is difficult, they do not listen to the teacher in the class on one hand, and on the other hand they are busy with the preparations for the CET 4. And they feel ashamed of having the college English classes as a sophomore - "It is ashamed to do the college English as a sophomore. Others who do not have the class look down upon you if they find you have an English course book in your hand, which really makes you lose face." As for the teachers, they think the teachers are patient with them, and give detailed explanations of the words, the texts, even the exercises after the texts. The teachers slow down their instructions giving the English level of the students. But the students feel this kind of teaching only serve to make them feel English more boring and cannot motivate them to study it. In addition, all the students in the class fail to pass CET4,but they indulge themselves in playing and do not bother to study English even though they feel panicked sometimes. They are worried that they fail to obtain their degrees for their poor English whereas they feel relaxed since many people are faced with the same situation - "I am not the only one who have not passed CET 4 and there are many people like me. It is impossible for the university to punish so many students."These students cannot be motivated by their classmates. Instead, they have bad effects on each other and they indulge themselves in playing without spending time and energy on their study.

\section{Methods to Motivate StUdents In ElEMENTARY CLASS}

\section{A. Improvement of Course Arrangement}

Improvement of course arrangements can fully utilize the students' instrumental motives and arouse students' English learning integrative motives. Given that the students in the elementary class hope to pass CET 4 greatly so as to gain their degrees, the course arrangements can cater to their desires and the teaching goal for the sophomores who still take college English course can be set as helping them pass CET 4. Specifically, the teaching contents can focus on the four aspects that CET 4 tests - listening, reading, translation and writing. The majority of teaching materials are the simulated and genuine CET 4 testing materials. Listening materials are combined with English songs, beautiful English essays and the excerpts of the movies and reading materials with current interesting English news. Translation instruction is combined with the comparisons and contrasts between English and Chinese in order to help students get rid of negative transference of mother language. Students' mistakes in their writings are explained in detail so as to improve their grammar.

\section{B. Strengthening Learning method Guidance}

Some students in the elementary class study hard but achieve little, which greatly affects their confidence of learning English well. Given that, teachers make some effort to know their learning and find that the reason of their failure in English learning is poor learning methods. Therefore it is necessary to guide their attribution of failure in order that they realize that their failure is attributed to their improper learning methods rather than their lack of language-learning talents, which can boost students' confidence. Meanwhile, teachers should consciously teach students some good learning methods. For example, teachers can inform students of the memory rules such as the Ebbinghaus forgetting curve. When the students learn Ebbinghaus forgetting curve reflects the memory rule that people forget things fast at first and slow later, they will review what they have learned in time so that they can memorize things better. When it comes to reading, it is necessary for teachers to cultivate students' ability to guess the meanings of words according to the contexts and their knowledge of roots and affix. Besides, teachers should encourage students to find their own effective learning methods and form good learning habits, such as persisting in studying English every day. With correct attribution of their failure, a good mastery of learning methods and good learning habits, students can perform well in their English learning, and then they will gain their confidence, improve their self-efficacy, strengthen their learning motives and transform their passive learning to active learning.

\section{Cultivation of Good Learning Environment}

Teachers should manage to improve their own teaching and research ability, flexibly utilize various teaching methods and assign proper homework in order to eliminate students' sense of inferiority and low self-efficacy and foster good learning environment. In the process of instruction, teachers should let the students in the elementary class understand that their current failure in CET 4 does not mean that they are doomed to fail. Then, teachers should persuade students to believe that the division of them is based on their English level, which has nothing to do with their intelligence and personalities. Besides, teachers should make students realize that language learning is a persistent one, which means that the passing of CET 4 does not predict the end of the English learning. In such cases, it is comparatively easy for students to get rid of their sense of inferiority. And teachers can promote the communication between students in the elementary class and those in intermediate and advanced class and found study teams consisting of students with different English levels, which helps found good learning environment under the influence of the students with a good command of English. Finally, teachers should actively make use of the advanced information technology to increase the language input for students. For example, English learning website is formed in Sichuan Agricultural University. 


\section{CONCLUSION}

Under the guidance of individualized quality education and on the basis of students' English level, the level-based English teaching mode is carried out in Sichuan Agricultural University in order to better the English instruction. But in the process, cultivating and strengthening of English learning motives are unfortunately dissatisfying. The author applies Dornyei's motive theory to analyze the English learning motives of students in the elementary class and put forward three methods to motivate them in hopes that it can be of some help to improve the current level-based English instruction.

\section{REFERENCE}

[1] Dornyei, Z. (1994). Motive and Motivating in the Foreign Language Classroom. Modern Language Journal,78, 273-284.

[2] Dornyei, Z. (2001). Motivational Strategies in the Language Classroom. Cambridge: Cambridge University Press.

[3] Dornyei, Z. \& Ema Ushioda.( 2011) Teaching and Researching Motive (2nd ed.). Longman, Harlow.

[4] Lambert,W.E. (1974). Culture and Language as Factors in Learning and Education. In Aboud F.E. \& Meade R.D. Cultural Factors in Learning and Education. Bell Ingham,Washington: Fifth Western Washington Symposium Learning, 91-122 